\title{
Monte Carlo Ray Tracing Simulation of Polarization Characteristics of Sea Water Which Contains Spherical and Non-Spherical Particles of Suspended Solid and Phytoplankton
}

\author{
Kohei Arai 1 \\ Graduate School of Science and Engineering \\ Saga University \\ Saga City, Japan
}

\author{
Yasunori Terayama 2 \\ Graduate School of Science and Engineering \\ Saga University \\ Saga City, Japan
}

\begin{abstract}
Simulation method of sea water which contains spherical and non-spherical particles of suspended solid and phytoplankton based on Monte Carlo Ray Tracing: MCRT is proposed for identifying non-spherical species of phytoplankton. From the simulation results, it is found that the proposed MCRT model is validated. Also some possibility of identification of spherical and non-spherical shapes of particles which are contained in sea water is shown. Meanwhile, simulations with the different shape of particles, Prolate and Oblate show that Degree of Polarization: DP depends on shapes. Therefore, non-spherical shape of phytoplankton can be identified with polarization characteristics measurements of the ocean.
\end{abstract}

Keywords- Monte Carlo Ray Tracing; Phytoplankton; Polarization characteristics.

\section{INTRODUCTION}

Red tide detection is getting more important. Due to some reason including global warming, red tide occurs more frequently and widely all over the coastal zone in the world. Harmful Algal Blooms: HABs ${ }^{1}$ are getting more severe situation. There are two types of red tide, spherical and nonspherical shapes of phytoplankton ${ }^{2}$ induced red tide. There is specific red tide phytoplankton to the coastal zones. For instance, Chattonella Antiqua ${ }^{3}$, Chattonella Marina ${ }^{4}$ is dominant phytoplankton in the Ariake $\mathrm{Sea}^{5}$ area, in Kyushu Island, Japan. Almost every summer, Chattonella phytoplankton appears in the Ariake Sea area. The shapes of these phytoplankton are different each other. Namely, Chattonella Antiqua has non-spherical shape while Chattonella Marina, Chattonella Globosa ${ }^{6}$ has relatively spherical shape. There is a strong demand on discrimination of spherical and non-spherical shapes of phytoplankton because it provides information on poison containing phytoplankton in some cases. It is possible to discriminate spherical and nonspherical shapes of phytoplankton by using polarization characteristics [1],[2]. Degree of polarization: DP [3] of the spherical shape of particles is almost zero while that of nonspherical shape of particles is greater than zero depending upon its spherical degree. Therefore, it is also possible to identify non-spherical shapes of phytoplankton through polarization measurements of sea surface with polarization radiometers or polarization cameras ${ }^{7}$.

Simulation study on discrimination of spherical and nonspherical particles can be done with Monte Carlo Ray Tracing: MCRT method [4]-[15]. MCRT simulation model for the atmosphere is proposed [4] while MCRT model for aerosol particle is proposed [5]-[7]. Meanwhile, MCRT for layered clouds is discussed [8] while MCRT models for representation of forest parameters are proposed [9]-[13]. In particular, forest Leaf Area Index: LAI model based on MCRT is proposed [14] while Bi-Directional Reflectance Distribution Function: BRDF model with MCRT is proposed for tea trees [15].

In this paper, simulation method is proposed then simulation results which show a validity of the method is described followed by some field experimental data which is also support a validity of the method. Then conclusion and some discussions are described finally.

\section{PROPOSED METHODS}

\section{A. Research Background}

The shapes of Chattonella Antiqua, Chattonella Marina are shown in Fig.1. Chattonella Antiqua has non-spherical shape while Chattonella Marina has relatively spherical shape as shown in Fig.1 clearly.

\footnotetext{
${ }^{1}$ http://en.wikipedia.org/wiki/Algal_bloom

${ }^{2} \mathrm{http}: / /$ en.wikipedia.org/wiki/Phytoplankton

${ }^{3} \mathrm{http}: / /$ www.minc.ne.jp/suishi/page022.html

${ }_{5}^{4}$ http://www.minc.ne.jp/suishi/page009.html

${ }^{5}$ Kohei Arai, Red Tides -Combines satellite and ground based detection-, SPIE Newsroom, 10/1117/2, 1201012, 003267, 2011.

${ }^{6} \mathrm{http}: / /$ www.marinespecies.org/hab/aphia.php?p=taxdetails\&id=246589
}

\footnotetext{
${ }^{7}$ http://www.sciencedirect.com/science/article/pii/026288569594383B
} 


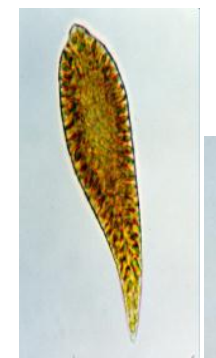

(a) Chattonella Antiqua

Figure 1 The shapes of Chattonella Antiqua, and Chattonella Marina

Polarization characteristics for both spherical and nonspherical phytoplankton are different obviously. Therefore, it might be possible to identify non-spherical phytoplankton through polarization measurement for sea surface with polarization radiometer or polarization camera. There are influences due to ocean waves, polarization on the sea surface, etc. on polarization measurement data. In order to avoid the influence due to ocean wave, the pixels of which normal direction of the sea surface is directed to zenith are extracted from the polarization camera images. Meanwhile, the influence due to polarization effect at the sea surface can be avoided by setting the looking angle at 53 degree (Brewster angle [3] of sea surface). Thus the polarization characteristics of the sea surface in concern are measured and estimated.

\section{B. Monte Carlo Ray Tracing: MCRT}

In order to show a validity of the proposed method for non-spherical phytoplankton, MCRT simulation study and field experimental study is conducted. MCRT allows simulation of polarization characteristics of sea surface with designated parameters of the atmospheric conditions and sea surface and sea water conditions. Illustrative view of MCRT is shown in Fig.2.

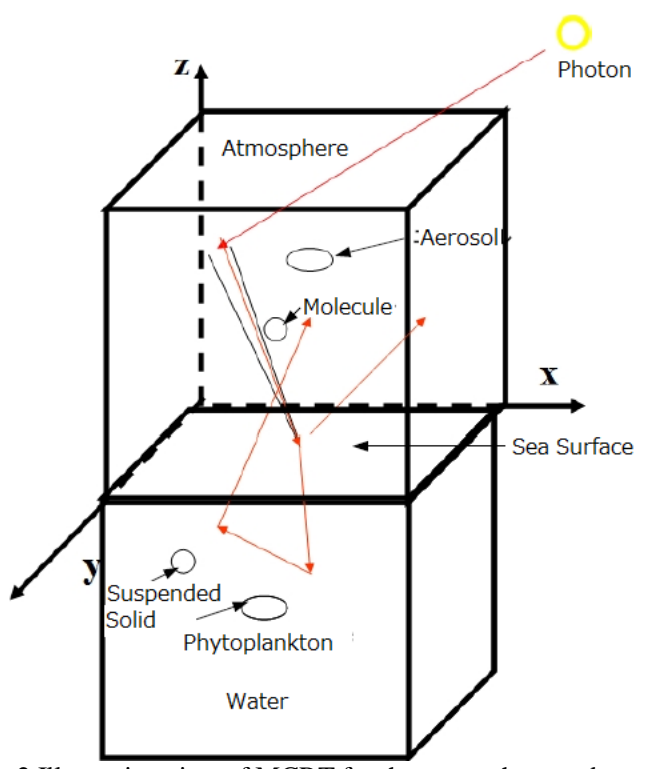

Figure 2 Illustrative view of MCRT for the atmosphere and sea water

Photon from the sun is input from the top of the atmosphere (the top of the simulation cell). Travel length of the photon is calculated with optical depth of the atmospheric molecule and that of aerosol. There are two components in the atmosphere; molecule and aerosol particles while three are also two components, water and particles; suspended solid and phytoplankton in the ocean. When the photon meets molecule or aerosol (the meeting probability with molecule and aerosol depends on their optical depth), then the photon scattered in accordance with scattering properties of molecule and aerosol. The scattering property is called as phase function. In the visible to near infrared wavelength region, the scattering by molecule is followed by Rayleigh scattering law [3] while that by aerosol is followed by Mie scattering law [3]. Example of phase function of Mie scattering is shown in Fig.3 (a) while that of Rayleigh scattering is shown in Fig.3 (b).

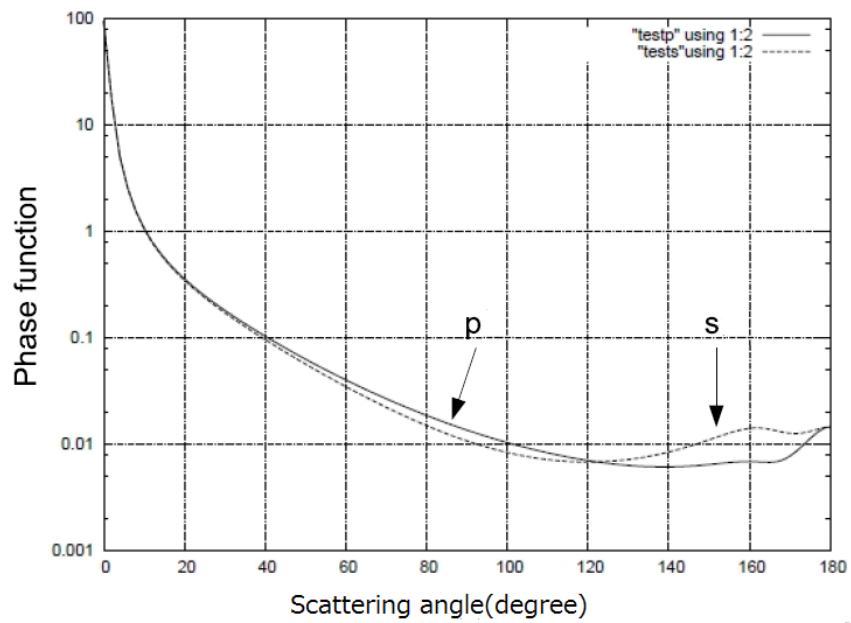

(a)Mie scattering

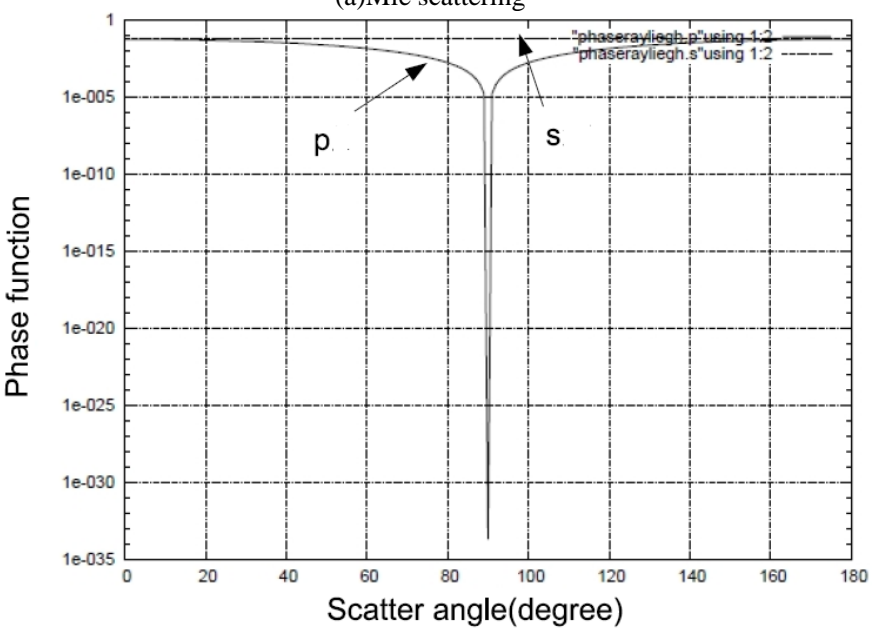

(b)Rayleigh scattering

Figure 3 Phase functions for Mie and Rayleigh scattering

In the figure, scattering angle is defined as the angle between incidence and reflected angle from the particle. These phase functions can be calculated with Mie Code in the MODerate resolution atmospheric TRANsmission; MODTRAN $^{8}$. In particular, Mie phase function depends on refractive index, size distribution, and shape of the aerosol particle in concern. For instance, phase function of prolate shape of particle differs from that of oblate shape of particle as shown in Fig.4.

${ }^{8}$ http://modtran.org/ 


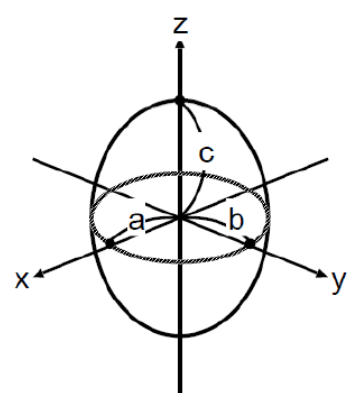

prolate : $a=b<c$ (a)Shapes of aerosol particles

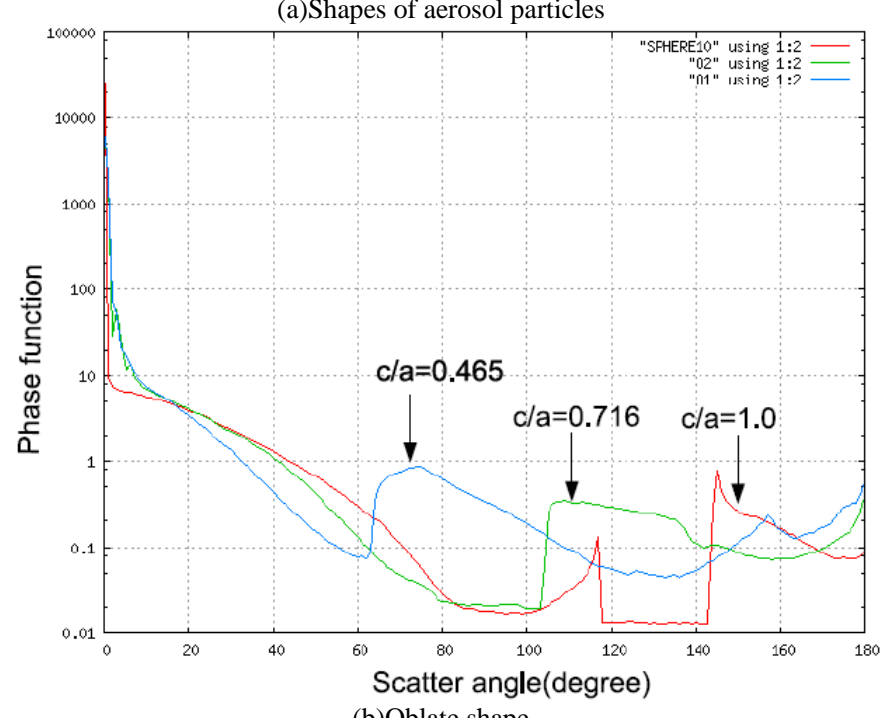

(b)Oblate shape

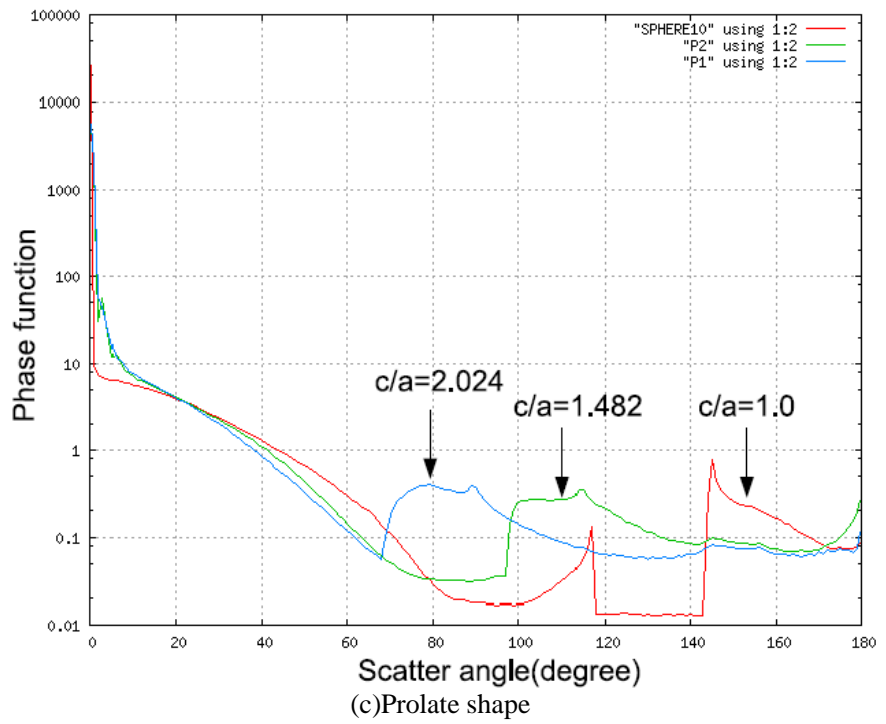

Figure 4 Two types of shape of aerosol particle and their phase functions as a function of the ratio of long radius and short radius.

The shapes of suspended solid and phytoplankton are assumed to be oblate or prolate of elliptical shape of which c/a ratio and orientation angle are to be random. In the MCRT simulation, these are aligned with the certain average interval (density of such materials) with the different c/a ratio and orientation together with refractive index of suspended solid and phytoplankton ${ }^{9}$.

Reflection, transpiration, and refraction of the photon at the sea surface are followed by Fresnell law [3] and Snell law [3] as shown in Fig.5.

Thus reflectance and transparency is calculated for $\mathrm{p}$ and $\mathrm{s}$ polarization separately together with total reflectance and transparency, Root Sum Square of $\mathrm{p}$ and $\mathrm{s}$ components as shown in Fig.6. Then the following Degree of Polarization: DP is calculated.

$$
\mathrm{DP}=(\mathrm{p}-\mathrm{s}) /(\mathrm{p}+\mathrm{s})
$$

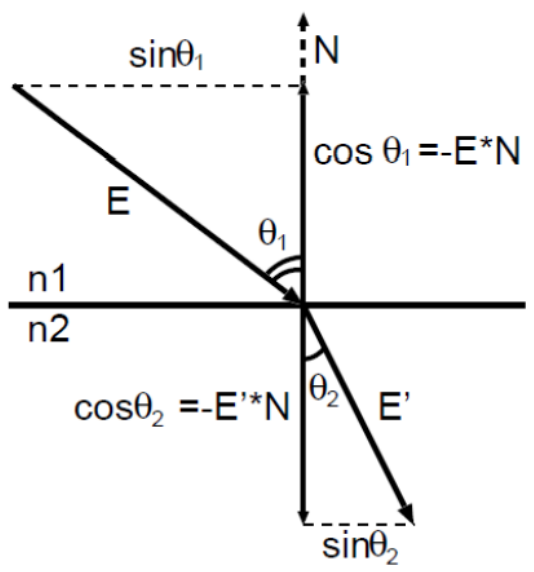

Figure 5 Reflection, transpiration, and refraction of the photon at the sea surface

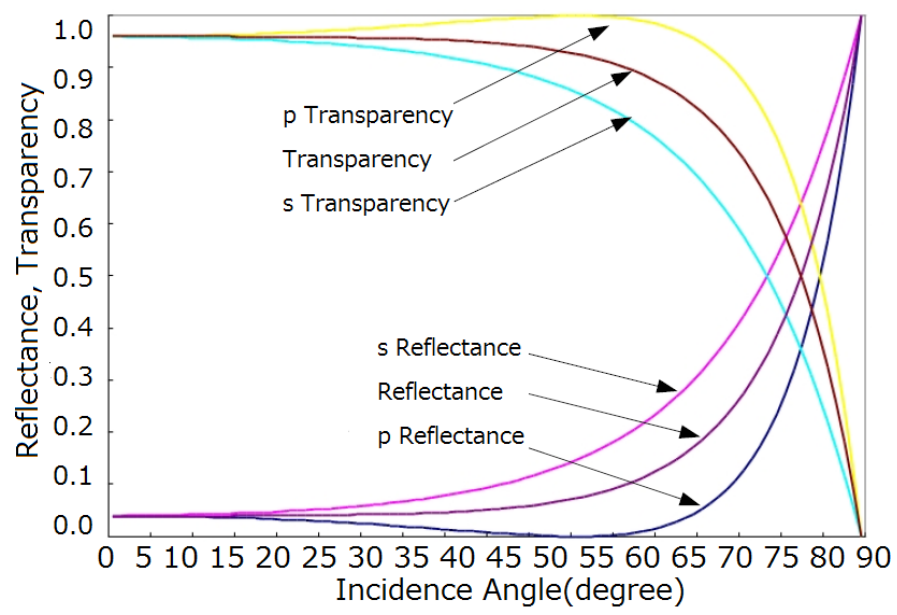

Figure 6 Reflectance and transparency is calculated for $\mathrm{p}$ and s polarization separately together with total reflectance and transparency, Root Sum Square of $\mathrm{p}$ and $\mathrm{s}$ components

\section{EXPERIMENTS}

\section{A. Overall Characteristics DP of Sea Surface at the Brewster Angle of Observations}

Fig.7 shows an example of MCRT simulation result of DP calculation at around Brewster angle of observation angle as a function of scattering angle. At the Brewster angle, $p$ reflectance is zero while s reflectance is around 0.14 as shown

\footnotetext{
${ }^{9}$ In this simulation, both refractive index of phytoplankton and suspended solid are assumed to be same.
} 
in Fig.6. Therefore, theoretical DP reaches at 1.0 and gradually decreases in accordance with increasing of scattering angle. Meanwhile, theoretical DP is increased with increasing of scattering angle ranges from zero to Brewster angle.

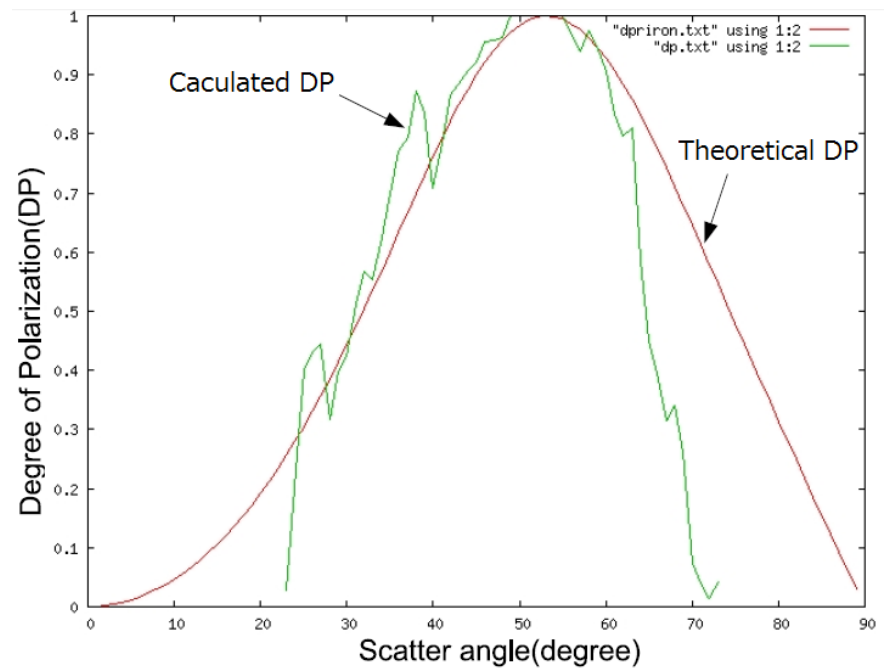

Figure 7 Example of MCRT simulation result of DP calculation at around Brewster angle of observation angle as a function of scattering angle

On the other hand, calculated DP (MCRT simulation result) shows the same trend with theoretical DP, the details are different though. MCRT simulation result of calculated DP goes up and down everywhere. One of the causes for these variations is that the number of photons is not enough. One of the conclusions from the MCRT simulation study is that observation angle has to be set at Brewster angle. Thus the polarization characteristics of the sea surface can be observed at the best observation condition.

\section{B. Reflectance Calculated Based on Monte Carlo Ray \\ Tracing: $M C R T$}

At the observation angle of 53 degree of Brewster angle, $p$ and $\mathrm{s}$ polarization reflectance are estimated with MCRT simulation. Table 1 shows the results.

TABLE I. P AND S REFLECTANCE FOR THE DIFFERENT OPTICAL DEPTH

\begin{tabular}{|l|l|l|}
\hline Optical Depth & P Reflectance & S Reflectance \\
\hline 0.01 & 0.07425 & 0.7641 \\
\hline 3.0 & 0.1218 & 0.8798 \\
\hline 5.0 & 0.1509 & 0.9106 \\
\hline
\end{tabular}

As shown in Fig.6, s reflectance is always greater than $p$ reflectance. The result shows the same trend. In the simulation, optical depth of the particles (suspended solid and phytoplankton) is changed from $0.01,3.0$, and 0.5 . On the other hand, reflectance of the sea surface is set at 0.1 . This implies that the transparency of sea water is set at 0.9. Thus DP can be calculated through $\mathrm{p}$ and $\mathrm{s}$ reflectance (using the difference of the number of photons for $\mathrm{p}$ and polarization of MCRT simulation results).

Table 2 shows total reflectance of particles containing sea water and sea water only as well as the deviations of reflectance and DP from the spherical shape of particle and from the reflectance for the sea water only. In the simulation, optical depth of the particles of suspended solid and phytoplankton is set at 3.0. Shapes of the particles of P1, P2 are set at 1.95 and 4.62 of c/a ratio while those of $\mathrm{O} 1, \mathrm{O} 2$ are set at 0.46 and 0.24 , respectively.

Particle size of these suspended solid and phytoplankton are same as spherical water. Therefore, equivalent scattering cross section of sea water only and of particle containing sea water are same.

TABLE II. T Otal Reflectance of Particles Containing Sea WATER AND SEA WATER ONLY AS WELL AS THE DEVIATIONS OF REFLECTANCE AND DP FROM THE SPHERICAL SHAPE OF PARTICLE AND FROM THE REFLECTANCE FOR THE SEA WATER ONLY WHEN THE PARTicLE Size IS NOT CHANGED DEPENDING UPON C/A RATIO.

\begin{tabular}{|l|l|l|l|}
\hline Shape & Reflectance & Deviation of reflectance (\%) & Deviation of DP \\
\hline O1 & 0.5 & 19.75 & 0.0136 \\
\hline O2 & 0.5 & 19.74 & 0.0127 \\
\hline Sphere & 0.499 & 19.51 & - \\
\hline Sea Water & 0.418 & - & - \\
\hline P2 & 0.5 & 19.74 & 0.0132 \\
\hline P1 & 0.5 & 19.75 & 0.0134 \\
\hline
\end{tabular}

Reflectance deviation of spherical shape of particle from the reflectance of sea water only is $19.51 \%$ while that of nonspherical particles is around $19.75 \%$. It is said that the reflectance of particles containing sea water is much different from that of sea water only while shape dependency of the reflectance is comparatively small, much smaller than that of the reflectance difference between sea water and particle containing sea water.

Meanwhile, the deviation of DP from the spherical shape of particle is varied depending upon c/a ratio in some extents. As is aforementioned, the particle orientations are random and are varied by time being. There are a variety of sizes for particles. Deviations of DP for the same size of different shapes and orientation angles of particles range from 0.0127 to 0.0136. Therefore, not so large influence due to the different shapes and orientation angles is suspected.

If the particle size is varied by the shape of particle, then the simulation result is remarkably changed from that of the case that the particle size is same even for the different shape. Table 3 shows the MCRT simulation results for that situation.

Due to the fact that scattering cross section is varied by the c/a factor, reflectance of the sea surface is changed with c/a factor as well as DP. The deviation of DP is totally depends on c/a ratio in this case. Because the averaged particle interval is same, cross section is dependent to c/a ratio.

TABLE III. T OTAL REFLECTANCE OF PARTICLES CONTAINING SEA WATER AND SEA WATER ONLY AS WELL AS THE DEVIATIONS OF REFLECTANCE AND DP FROM THE SPHERICAL SHAPE OF PARTICLE AND FROM THE REFLECTANCE FOR THE SEA WATER ONLY WHEN THE PARTICLE SizE IS CHANGED DEPENDING UPON C/A RATIO.

\begin{tabular}{|l|l|l|l|}
\hline Shape & Reflectance & Deviation of reflectance (\%) & Deviation of DP \\
\hline O1 & 0.577 & 57.70 & 0.0167 \\
\hline O2 & 0.575 & 57.51 & 0.00379 \\
\hline Sphere & 0.169 & 16.87 & - \\
\hline Sea Water & 0.1 & - & - \\
\hline P2 & 0.136 & 13.58 & 0.00199 \\
\hline P1 & 0.127 & 12.66 & 0.00298 \\
\hline
\end{tabular}




\section{CONCLUSION}

Monte Carlo Ray Tracing: MCRT based simulation method of sea water which contains spherical and nonspherical particles of suspended solid and phytoplankton is proposed. Using the proposed method, identifying nonspherical species of phytoplankton is available. From the simulation results, it is found that the proposed MCRT model is valid. Also some possibility of identification of spherical and non-spherical shapes of particles which are contained in sea water is shown. Meanwhile, simulations with the different shape of particles, Prolate and Oblate show that Degree of Polarization: DP depends on shapes. Therefore, non-spherical shape of phytoplankton can be identified with polarization characteristics measurements of the ocean.

\section{ACKNOWLEDGMENT}

The authors thank laboratory staff and members for their discussions and valuable comments as well as suggestions through MCRT simulation study. In particular, the author thanks Miss.Yoko Takamatsu for her great effort to create phase function of suspended solid and phytoplankton particles.

\section{REFERENCES}

[1] Kohei Arai and Yasunori Terayama, A method for red tide detection and discrimination of red tide type(spherical and non-spherical shapes of red tide) through polarization measurements of sea surface, International Journal of Applied Science, 2, 3, 62-70, 2011

[2] Kohei Arai and Yasunori Terayama, Satellite and Ground based red tide detection method and system by means of peak shift of remote sensing reflectance, International Journal of Applied Science, 2, 3, 53-61, 2011

[3] Kohei Arai, Lecture Note on Remote Sensing, Morikita-Shuppan Publishing Incorporation, 2004.

[4] Tsutomu Takashima, Kazuhiko Masuda and Kohei Arai, Measurements of skylight polarization with surface reflectance over Railroad Valley, Nevada, Papers in Meteorological Geophysics, Vol.50, No.3, pp.113124, 1999

[5] Kohei Arai, Influence of non-spherical shape of sea salt aerosol particle on the top of the atmosphere radiance, Journal of Japanese Remote Sensing Society, Vol.20, No.5, pp.32-39, (2001).

[6] Kohei Arai and Yoko Takamatsu, Phase function of relatively large size of sea salt aerosol particle containing bubbles, Journal of Japanese Remote Sensing Society, Vol.22, No.1, pp.40-49, 2002.
[7] Kohei Arai, Phase function of relatively large aerosol particles containing bubbles by means of a Ray Tracing, Advances in Space Research, Vol.29, No.19, 1813-1818, 2002.

[8] Kohei Arai, Adjacency effect of layered clouds estimated with MonteCarlo simulation, Advances in Space Research, Vol.29, No.19, 18071812, 2002.

[9] Kohei Arai and Yoko Takamatsu, Influence of spume aerosol particle on the top of the atmosphere radiance, Journal of Japanese Remote Sensing Society, Vol.23, No.4, pp.355-363, 2003.

[10] Shigeki Kuzuoka and Kohei Arai, Forest parameter estimation based on Monte Carlo Ray Tracing, Journal of Japanese Remote Sensing Society, Vol.22, No.4, pp.394-404, 2003.

[11] Kohei Arai and Yaliu Ding, Reflection model taking into account multiple reflection between trees, Journal of Japan Society of Photogrammetry and Remore Sensing, 45, 6, 56-66.2006

[12] Yaliu Ding and Kohei Arai, Forest parameter estimation based on MCRT based radiative transfer model, Journal of Japanese Remote Sensing Society, 27, 2, 141-152, 2007

[13] Yaliu Ding, Kohei Arai, Forest parameter estimation, by means of Monte-Carlo simulations with experimental consideration of estimation of multiple reflections among trees depending on forest parameters, Advances in Space Research, 43, 3, 438-447, 2009.

[14] Kohei Arai and Yui Nishimura, Polarization model for discrimination of broad and needle shaped leaves and estimation of LAI using polarization measurements, Advances in Space Research, 44, 510-516, 2009.

[15] Kohei Arai, Monte Carlo ray tracing simulation for bi-directional reflectance distribution function and grow index of tealeaves estimation, International Journal of Research and Reviews on Computer Science, 2, 6, 1313-1318, 2011.

\section{AUTHORS PROFILE}

Kohei Arai, He received BS, MS and PhD degrees in 1972, 1974 and 1982, respectively. He was with The Institute for Industrial Science, and Technology of the University of Tokyo from 1974 to 1978 also was with National Space Development Agency of Japan (current JAXA) from 1979 to 1990. During from 1985 to 1987, he was with Canada Centre for Remote Sensing as a Post-Doctoral Fellow of National Science and Engineering Research Council of Canada. He was appointed professor at Department of Information Science, Saga University in 1990. He was appointed councilor for the Aeronautics and Space related to the Technology Committee of the Ministry of Science and Technology during from 1998 to 2000. He was also appointed councilor of Saga University from 2002 and 2003 followed by an executive councilor of the Remote Sensing Society of Japan for 2003 to 2005. $\mathrm{He}$ is an adjunct professor of University of Arizona, USA since 1998. He also was appointed vice chairman of the Commission "A" of ICSU/COSPAR in 2008. He wrote 30 books and published 332 journal papers. 